\title{
A DISCIPLINA JURÍDICA DOS CONTRATOS DE REPRESENTAÇÃO COMERCIAL AUTÔNOMA E AGÊNCIA.
}

\author{
Elton Nunes José Alves*
}

\begin{abstract}
RESUMO: O presente trabalho objetiva relacionar o contrato de representação comercial autônoma (Lei n 4.886/65) com o contrato de agência (Artigos 710 a 721, do Código Civil). A pesquisa é bibliográfica e documental, utilizando-se o método dedutivo. Apresenta-se o histórico do surgimento dos auxiliares do comércio, o surgimento no Brasil da disciplina jurídica dos representantes comerciais, assim como o histórico legislativo da criação da lei de representação comercial. Defende-se a hipótese de que os contratos são distintos, cada qual com disciplina normativa própria, tendo-se como marco distintivo o registro profissional para diferenciar a figura do representante comercial da do agente.
\end{abstract}

Palavras-chave: Contratos empresariais; Representação Comercial; Agência.

\section{THE LEGAL DISCIPLINE OF COMMERCIAL REPRESENTATION AGREEMENT AND AGENCY CONTRACT.}

\begin{abstract}
The present work aims to relate the commercial representation agreement (Law 4.886/65) and the agency agreement (Articles 710 to 721, of the Civil Code). The research is bibliographical and documentary, using the deductive method. We present the history of emergence of auxiliaries of commerce, the emergence in Brazil of the legal discipline of commercial representatives and the legislative history of the creation of the law of commercial representation. The hypothesis is that the contracts are distinct, each one with its own normative discipline, as distinctive mark the professional registry to differentiate the figure of the commercial representative from the agent.
\end{abstract}

Keywords: Business contracts; Commercial representation; Agency.

\section{Introdução}

O presente artigo tem por objetivo relacionar o contrato de representação comercial autônoma com o de agência, de modo a verificar se existe identidade entre tais contratos. A

\footnotetext{
* Bacharel em Direito pela UERJ. Mestrando em Direito pela UERJ na linha de pesquisa Empresa e Atividades Econômicas. Advogado. Correio eletrônico: eltonnunes2003@yahoo.com.br
} 
pergunta principal que conduz a investigação, no âmbito dos contratos empresariais, é: Qual a razão de o Código Civil de 2002 regular o contrato de agência (artigos 710 a 721) se a mesma atividade, a mediação para promover negócios à conta de outrem, em espaço geográfico determinado, já era devidamente regulada na lei 4.886/1965, que regulamenta a profissão de representante comercial, e quais seriam as consequências jurídicas de tal escolha? A pesquisa, de caráter bibliográfico e documental, utilizará o método dedutivo, com a análise de dispositivos legais, de modo a extrair a essência dos dispositivos à luz da racionalidade e estabilidade do ordenamento jurídico, assim como em diálogo com a doutrina sobre o tema.

O contrato de agência assemelha-se ao contrato de representação comercial autônoma, regulado pela lei 4.886/65, existente no direito brasileiro, portanto, há muito tempo. Vale a pena citar os conceitos trazidos pelas respectivas leis.

Diz o artigo $1^{\circ}$ da lei $4.886 / 65$, que regula as atividades dos representantes comerciais autônomos: “Artigo $1^{\circ}$, da lei 4.886/65: Exerce a representação comercial autônoma a pessoa
jurídica ou a pessoa física, sem relação de emprego, que desempenha, em caráter não
eventual por conta de uma ou mais pessoas, a mediação para a realização de negócios
mercantis, agenciando propostas ou pedidos, para, transmiti-los aos representados,
praticando ou não atos relacionados com a execução dos negócios”.
O artigo 710, do Código Civil, assim apresenta o contrato de agência:

“Art. 710. Pelo contrato de agência, uma pessoa assume, em caráter não eventual e sem vínculos de dependência, a obrigação de promover, à conta de outra, mediante retribuição, a realização de certos negócios, em zona determinada, caracterizando-se a distribuição quando o agente tiver à sua disposição a coisa a ser negociada”.

Da leitura dos dispositivos legais supracitados, verifica-se a similitude dos institutos, que tratam da mesma atividade econômica, a mediação para conclusão de negócios, à conta de outrem. Assim, a criação do contrato de agência pelo Código Civil de 2002 gerou (e ainda gera) grande discussão doutrinária. O debate reside na discussão de se o contrato de agência seria um contrato distinto do de representação comercial autônoma ou se, ao contrário, o contrato de agência seria idêntico ao contrato de representação comercial, sob nova roupagem dada pelo código civil. A tentativa aqui é apresentar a relevante discussão doutrinária assim como as consequências jurídicas da teoria adotada, a revelar consequências práticas importantes.

A hipótese do trabalho é de que os contratos de representação comercial autônoma e agência são distintos, embora tratem da mesma empresa. Antes, todavia, mostra-se importante abordar, ainda que brevemente, o histórico do surgimento dos agentes auxiliares do comércio, o contrato de representação, seu surgimento, características e classificação. 
1. O florescer do comércio e a necessidade de mediação para a realização de negócios.

A Idade Média viu surgir o nascimento da cidade e, com ela, do comércio. Com efeito, a partir do século XI, as estruturas econômicas sofreram uma profunda transformação. Conforme afirma Guy Antoneti, "na história do desenvolvimento econômico da Europa Ocidental a revolução do século XI foi relativamente tão importante quanto foram as do século XVI e XVIII” (ANTONETTI, 1977, p.15). Isso porque, segundo o autor, houve neste período o crescimento sensível da população e a melhoria da produção agrícola, o renascimento das cidades, o desenvolvimento das trocas e a expansão colonial que transformaram a economia dominial rural da Alta Idade Média em economia artesanal urbana. Até o século XIII, o grande comércio intercontinental era também um tráfico itinerante, pois o mercador acompanhava sua mercadoria, vendia-a ao fim de sua viagem e voltava com uma grande quantidade de produtos. Segundo o historiador Jacques Le Goff (1991, p.14), “no século XIII, a grande meta do mercador itinerante são as feiras da Champagne”.

No decorrer do século XIII, entretanto, cada vez mais o grande mercador preferirá permanecer em sua casa, pois, por razões fiscais, os reis e os grandes senhores ofereciam a ele especial proteção. Com o declínio das feiras já no início do século XIV, o mercador itinerante, também conhecido como “pé empoeirado”, dá paulatinamente lugar ao mercador sedentário. Assim, cercado de poucas pessoas, o grande mercador redigia e recebia correspondências que o mantinha em estreita relação com seus associados ou correspondentes de outros lugares. Desta maneira, ele podia dirigir de longe vários negócios de uma só vez. Conforme afirma Antonetti (1977, p.89), “esse movimento de sedentarização, aparecido inicialmente na Itália, difundiu-se em seguida no norte da Europa: nos séculos XIV-XV os grandes mercadores italianos ou hanseáticos eram sedentários e, por conta deles, os comissionados se deslocavam”. Percebe-se, portanto, que na Idade Média se dá especialmente a gênese dos auxiliares do comércio, de destacada importância para o desenvolvimento das atividades comerciais.

De fato, a Idade Média conheceu acentuado desenvolvimento do comércio e facilidade nas relações comerciais entre diversas regiões ou países. Com a extensão dos mercados, já não era mais possível ao produtor fornecer diretamente ao comprador. E, conforme pontua Rubens Requião (1977, p.6), “para que a riqueza pudesse transpor longas distâncias (...) foram surgindo entrepostos, armazenadores, comissários, transportadores, viajantes comerciais, representantes comerciais e outros intermediários com as características modernas”. É com o desenvolvimento

\footnotetext{
${ }^{1}$ Cf. LE GOFF, Jacques. Mercadores e banqueiros da Idade Média. São Paulo: Martins Fontes, 1991, p.14.
} 
das cidades, no ambiente urbano, que floresce o comércio medieval, sendo, portanto, neste contexto que se desenvolve o mercador medieval.

A Antiguidade, por sua vez, não conheceu a figura do representante comercial autônomo e do agente tal como o concebemos atualmente ${ }^{2}$. No direito romano, instituto semelhante ao da agência seria o do procuratio, que teria o mesmo significado de agência, ou de administração de negócios de outro ${ }^{3}$. O agente, em Roma, era chamado de procurador, que assim era definido: "Procurator est, qui aliena negotia mandatos domini administrat".

A agência, conforme expõe Joseph Story (1869, p.3) no seu aprofundado trabalho sobre Law of agency, escrito ainda no século XIX, era às vezes também chamada, em sentido amplo, de mandatum (mandato). No entanto, o mandato só poderia se dar se fosse gratuito. Caso houvesse alguma remuneração, estaríamos diante da locatio et conductio, uma espécie de contrato de locação de serviços ${ }^{56}$. É o que expressa o brocardo latino mandatum, nisi gratuitum, nullum est, nam originem ex officio et amicitia, trahit. Contrarium ergo est officio merces; interveniente enim pecunia, res ad locationem et conductionem potius respicit ${ }^{7}$. Conforme ensina Rubens Requião (2005, p.3), “no Direito Romano, com efeito, o contrato de mandato era concebido para negócios isolados, prestados de forma gratuita. Desconhecia-se o mandato como capaz de fundamentar uma atividade profissionalizante”.

Verifica-se, portanto, que havia certa confusão entre os institutos jurídicos. Não existia a figura da representação comercial como categoria jurídica autônoma, própria e distinta de institutos jurídicos próximos, tal como o do mandato e locação de serviços. No direito romano,

\footnotetext{
${ }^{2}$ Embora haja pesquisadores que identificam o nascimento do termo "agente" com origem do agens romano. Cf.: MCGAW, M.C. A history of the common law of agency with particular reference to the concept of irrevocable authority coupled with an interest. Tese de doutorado: University of Oxford: (United Kingdom), Ann Arbor, 2005. ${ }^{3}$ Cf. STORY, Joseph. Commentaries of the Law of Agency as a Branch of Commercial and Maritime Jurisprudence, With Occasional Illustrations From the Civil and Foreign Law. Boston: Little Brown, and Company, 1869, p.3.

${ }^{4}$ Tradução livre: "Procurador é aquele que administra os negócios alheios por mandato do titular".

${ }^{5}$ Para maior aprofundamento sobre o tema, ver STORY, Joseph. Commentaries of the Law of Agency as a Branch of Commercial and Maritime Jurisprudence, With Occasional Illustrations From the Civil and Foreign Law. Boston: Little Brown, and Company, 1869. Para este tópico em específico, consultar páginas 3-4.

${ }^{6}$ No contrato de locação de serviços, com raízes na locatio operarum do Direito Romano, seu objeto é uma prestação de fazer, porém encarada tal prestação como resultado e não como processo, do que distingue do contrato empregatício, no qual vislumbra-se a prestação de fazer como um processo constante e relativamente indeterminado. Cf. DELGADO, Maurício Godinho. Trabalho autônomo. In.:Curso de Direito do Trabalho, 6. ${ }^{\text {a }}$ edição. São Paulo: Ed. Ltr, 2007, p. 336.

7 "Um mandato não existe a não ser que seja gratuito, pois tira a sua origem do dever e da amizade, e o pagamento é incompatível com esse dever. (A mandate does not exist unless it is gratuitous: for it draws its origin from duty and friendship, and payment is incompatible with duty). Tradução livre, do inglês, da obra KEHOE, Dennis P. \& MCGINN, Thomas A. J. (eds.). Ancient law, ancient society. Ann Arbor: University of Michigan Press, 2017,p. 113.
} 
outrossim, os efeitos do ato, em regra, recaíam diretamente sobre seu agente, pois havia a completa abstração do mandante, o que dificultava ainda mais a tarefa da representação. As atividades comerciais em Roma também sempre foram marcadas por grande preconceito, a dificultar a criação e desenvolvimento do comércio, que começou a florescer, como vimos, especialmente na Idade Média.

Ainda em relação aos povos antigos, na Grécia, a propriedade de imóveis, rurais e urbanos, era reservada exclusivamente aos cidadãos. Os metecos (estrangeiros admitidos a viver na polis) podiam adquirir bens móveis e possuir escravos, mas nunca terras ou casas, salvo algumas exceções. Assim, aos metecos restavam como opção de profissão o comércio e artesanato, por isso mesmo atividades consideradas vis, embora reconhecidas como necessárias ${ }^{8}$.

Sendo assim, o representante comercial aqui em análise surge especialmente na Idade Média, juntamente com o desenvolvimento do comércio e da crescente complexidade das relações comerciais.

\section{A representação comercial no Brasil}

O Código Comercial Brasileiro de 1850 não tratou da representação comercial autônoma. Conforme consta na Justificação ao Projeto de Lei 1.171/1949 ${ }^{9}$, elaborado pelos Sindicatos de Representantes Comerciais do Brasil, encarregado o sindicato paulista de elaborar o anteprojeto, o nosso Código Comercial não se preocupou em regulamentar a figura do representante comercial, mesmo porque a representação comercial praticamente não existia naqueles tempos. Com efeito, o Código foi elaborado para um país que saía do regime colonial, de portos fechados e economia incipiente. À medida que as condições econômicas do país foram se modificando e o Brasil passou a ter um comércio mais ativo e próspero, intensificando as suas relações comerciais, novos institutos foram acrescentados à nossa legislação comercial, a necessitar de regulamentação específica. Nesse contexto, percebeu-se a necessidade de regular a profissão do representante comercial, de modo a prover a necessária segurança jurídica entre representantes e representados.

\footnotetext{
${ }^{8}$ Sobre o tema, cf. COMPARATO, Fábio Konder. A Civilização capitalista: para compreender o mundo em que vivemos. São Paulo: Saraiva, 2013, p. 40.

${ }^{9}$ BRASIL. Câmara dos Deputados - Projeto de Lei n. 1.171, de 1949 - Protocolo n. 0242. Deputado Campos Vergal.
} 
O fato de o Código Comercial de 1850 não ter regulado o contrato de representação comercial não significa dizer, todavia, que à época do Código não existisse essa figura jurídica. Com brilhantismo, os professores Alexandre Ferreira de Assumpção Alves e Pedro Freitas Teixeira, num didático e substancioso artigo sobre a matéria, explicam:

\begin{abstract}
"Muito embora não estivesse tipificada no Código Comercial dentre os contratos mercantis nem fosse listada como ato de comércio no art. 19 do Decreto $\mathrm{n}^{\circ}$ $737 / 1850^{10}$, a representação comercial já era reconhecida como atividade profissional e mercantil na primeira metade do século. Diferentemente dos tradicionais contratos de mandato mercantil, comissão e corretagem, figuras contratuais típicas e clássicas, a atividade de representação comercial e as relações do representante com o representado passaram a exigir do legislador regulamentação própria, com o objetivo de estabilizar as relações entre representantes e representados, dando-lhes segurança jurídica na contratação”(ALVES; TEIXEIRA, 2015, p.230).
\end{abstract}

O Código Comercial tratou da figura dos caixeiros (artigo 35, 3, do Código Comercial de 1850), daí o nome caixeiros viajantes, agentes auxiliares do comércio, conforme o Título 3 do Código Comercial Brasileiro. Pode-se afirma que o representante comercial surge da evolução das atividades dos caixeiros, como agentes auxiliares do comércio que já faziam atividades de intermediação. Como afirma Paulo Araújo (2011, p. 27), “trata-se da evolução do 'caixeiro viajante', o mascate, que atravessava os mais distantes rincões para levar a quem quisesse comprar mercadorias das mais diversas. (...) Esses agentes agiriam por si (...), constituindo a longa mão da empresa" ${ }^{11}$.

No processo de reconhecimento da profissão, informa Rubens Requião (2005, p.4) que, “enquanto se discutia na doutrina a tutela dos direitos do agente comercial, pleiteavam eles, coincidentemente, em diversos países, o reconhecimento e instituição de uma disciplina legal para o contrato e para a sua atividade profissional”. Assim, o autor destaca que os agentes e representantes de comércio, na Itália e França ${ }^{12}$, unidos em federação desde 1905, reclamaram

\footnotetext{
${ }^{10}$ Rubens Requião, no seu Curso (REQUIÃO, Rubens. Curso de direito comercial. $23^{a}$ ed. São Paulo: Saraiva, 1998), traz a discussão de se o representante comercial seria comerciante ou se sua atividade seria de natureza civil, tendo em vista "a posição doutrinária adotada por Juntas Comerciais que negavam o arquivamento de declaração de firmas individuais, ou de atos constitutivos de sociedades, cujo objeto simplesmente é a representação comercial, porque as consideram de natureza civil” (idem, p. 186). Essa discussão se tornou ultrapassada considerando a adoção da teoria da empresa pelo Código Civil de 2002, que acabou com a dicotomia entre atividade civil e atividade comercial.

${ }^{11}$ Cabe aqui, ainda que brevemente, estabelecer algumas diferenças com figuras afins. Na representação, o representante apenas angaria negócios para o representado. No mandato (art. 653, do Código Civil) o mandatário representa o mandante. Na comissão (art. 694, do Código Civil), o Comissário age e se obriga perante terceiros. Na corretagem, uma pessoa, não ligada a outra em virtude de mandato, de prestação de serviços ou por qualquer relação de dependência, obriga-se a obter para a segunda um ou mais negócios, conforme as instruções recebidas (art. 722, do Código Civil).O corretor, diferente do representante comercial, não tem zona geográfica definida.

${ }^{12}$ Interessante notar que no direito francês há a distinção entre o representante comercial e o agente comercial. Ao representante comercial se aplica legalmente ao representante dependente, empregado, ao passo que ao agente
} 


\section{A DISCIPLINA JURÍDICA DOS CONTRATOS DE REPRESENTAÇÃO COMERCIAL} AUTÔNOMA E AGÊNCIA.

urgentemente em publicações e congressos uma legislação especial. Cesar Vivante, nomeado para elaborar o projeto de Reforma do Código de Comércio, em 1920, ocupou-se de regular a disciplina jurídica dos agentes. Diz o famoso comercialista no anteprojeto, citado por Rubens Requião:

A classe importante dos agentes de comércio será regulada pela primeira vez no Código de Comércio, levando em consideração os votos e os projetos que ela formulou em numerosos congressos, das informações prestadas pessoalmente pelos seus representantes, e dos exemplos fornecidos pela legislação estrangeira” (VIVANTE, 1921, p.614. Apud: REQUIÃO, 2005, p.4).

O Código Civil italiano de 1942 instituiu a disciplina do contrato de agência no seu artigo 1.742 e seguintes. A França, por sua vez, reconheceu a especificidade do papel do agente comercial por anos e em 23 de dezembro de 1958 editou lei (The Registre Spécial des Agents Commerciaux - RSAC) $)^{13}$ garantindo proteção específica do agente e organizou um processo de registro para o desempenho da função ${ }^{1415}$. Todo esse movimento legislativo se deu em razão da união e reunião de esforços dos representantes comerciais para verem suas reinvindicações tuteladas pelo ordenamento jurídico.

No Brasil não se deu de forma diferente. Noticia o processualista Humberto Teodoro Júnior que, “tal como passava na Europa, também no Brasil, a reivindicação de um regulamento legal para a profissão do representante comercial autônomo tornou-se a maior aspiração dos órgãos representativos da categoria” (2002, p. 135). Na II Conferência Nacional das Classes Produtoras, realizada em Araxá, no ano de 1949, aconteceu o primeiro movimento próregulamentação específica da categoria dos representantes comerciais. Em São Paulo, conforme relatam Alexandre Ferreira Assumpção Alves e Pedro Teixeira Freitas (2015, p.231), “realizouse o $1^{\circ}$ Congresso Nacional de Representantes Comerciais, cujo objetivo principal era o de dar seguimento às reivindicações antes aprovadas pela II Conferência de Araxá”.

\footnotetext{
comercial se destina a nomear o representante comercial autônomo. No Direito brasileiro, são usados indistintamente os dois termos para nomear o intermediário profissional autônomo. Vide REQUIÃO, 2005, p. 5.

13 Informação fornecida por: MOQUIN, Arnaud. Commercial agent Contract: France. Disponível em: http://www.e-iure.com/pdf/agency/2007/france.pdf. Acessado em 07/03/2018.

${ }_{14}$ Essa lei sofreu diversas alterações. Atualmente na França o agente comercial é regulado no Código Comercial (Seção L 134-1 a L 134-17).

${ }^{15}$ A título de registro, o direito alemão incluiu a disciplina do representante comercial no seu Código Comercial (HGB), em 10 de maio de 1897, na seção VII, do artigo 84 até o artigo 92-C. Vários países já têm regulamentação específica sobre o contrato de representação ou agência comercial, tais como a Lei Suíça de 4 de fevereiro de 1949 (incluída no art. 418, do Código de Obrigações); o Código de Comércio Japonês, de 1951 (art.46, et seq.), e na Argentina, a Lei $n^{\circ}$ 14,546, de 27 de outubro de 1958 (REQUIÃO, 2005, p.7). Vários países europeus regularam o contrato de representação comercial após a edição da Diretiva da Comunidade europeia, de 18 de dezembro de 1986, relativa à coordenação do direito dos Estados-membros sobre os agentes comerciais (86/653/CEE).
} 
Assim, em 13 de dezembro de 1949 foi apresentado o Projeto de Lei ${ }^{\circ} 1.171$, do deputado Campos Vergal, no qual dispôs sobre as características do representante comercial. Esse Projeto, no entanto, não foi convertido em Lei ${ }^{16}$, apesar de inúmeras vezes renovado e de sua aprovação na Comissão de Constituição e Justiça em 02 de maio de 1950.

Em 1961, o Projeto n 2.704/61 foi apresentado pelo deputado Barbosa Lima Sobrinho. No Senado, o substitutivo sob o $\mathrm{n}^{\circ} 38 / 63$ foi finalmente aprovado no âmbito legislativo. A justificativa inicial do Projeto de Lei apresentada pelo deputado foi de que a Lei $\mathrm{n}^{\circ} 3.207$, de 18 de junho de 1957, regulamentou as atividades dos vendedores, viajantes ou pracistas, mas permanecia sem qualquer proteção legal a atividade dos representantes comerciais autônomos. Ressalta o proponente que este Projeto não era o primeiro a surgir no Congresso. Com efeito, dois projetos anteriores - o de $n^{\circ} 67$, de 1951, e o de $n^{\circ} 1.444$, de 1956, cuidaram da matéria, mas não chegaram a ter parecer na Comissão de Constituição e Justiça ${ }^{17}$.

O projeto 2.704/61 foi totalmente vetado pelo Presidente da República Humberto de Alencar Castelo Branco (1964-1967). A justificativa para o veto foi de que o Projeto, nos termos em que estava redigido, restringia demasiadamente a liberdade de contratar, dando ao contrato de representação comercial feição imprópria que praticamente o equiparava ao contrato de trabalho $^{18}$. O Presidente da República reconheceu a importância de disciplinar o contrato de representação comercial e, embora tenha vetado o Projeto anterior, determinou, por intermédio do Ministério da Indústria e Comércio, que se constituísse Comissão com representantes da Confederação Nacional da Indústria e da Confederação Nacional do Comércio para apresentar Projeto de Lei para regular a matéria. Assim foi feito. Do Projeto de Lei $n^{\circ} 3.350$, de 17 de novembro de 1965 nasceu a Lei 4.886, de 9 de dezembro de 1965, em vigor até hoje, modificada pelas Leis 8.420, de 8 de maio de 1992 (que introduz alterações na Lei de referência, que regula as atividades dos representantes comerciais autônomos e confere diversos direitos aos representantes) e Lei 12.246, de 27 de maio de 2010 (que altera dispositivos da Lei $n^{\circ}$ 4.886, de 9 de dezembro de 1965, para dispor sobre fixação do valor das anuidades, taxas e

\footnotetext{
${ }^{16}$ Cabe consignar o ilustrado comentário de Alexandre Assumpção e Pedro Freitas no sentido de que "apesar do insucesso do Projeto de Lei, é importante destacar (...) que esta foi a primeira e a única tentativa de regulamentar a profissão de representante comercial dissociada da figura do agente, conforme apontava 0 art. $1^{\circ}$ do Projeto" (idem, p.232).

${ }^{17}$ Cf. BRASIL. Câmara dos Deputados - Emendas do Senado ao Projeto de Lei n. 2704, de 1961. Deputado Barbosa Lima Sobrinho.

${ }^{18}$ Cf. BRASIL. Exposição de motivos n 355, de 1965, do Ministro da Indústria e Comércio, p. 6. Disponível em : $\quad$ http://www.camara.gov.br/proposicoesWeb/prop_mostrarintegra?codteor=1194993\&filename=Dossie+PL+3350/1965. Acessado em: 08 de março de 2018.
} 
emolumentos devidos pelos profissionais da categoria e pelas pessoas naturais e jurídicas aos Conselhos Regionais dos Representantes Comerciais em que estão registrados), de modo a conferir a necessária segurança jurídica no relacionamento entre representantes e representados.

Como fundamento para criação da lei, explica-se que “a falta de regulamentação específica da representação comercial criava casos de flagrantes injustiças, sendo mais comuns os de dispensa sem justo motivo dos representantes, após estes terem formado uma clientela sólida e confiável para o representado (idem, p.235)”. No mesmo sentido, o parecer de Barbosa Lima Sobrinho (1961):

“O representante forma uma clientela apreciável e de um dia para o outro é despedido,
sem compensação, para que a empresa se beneficie com a extinção das comissões
correspondentes ao esforço do representante. Os franceses classificam essa maneira
de agir como “la tactique du presse citron”, o que poderíamos traduzir como a tática
de espremer limões, tirando fora a casca, desde quando obtido todo o sumo que ele
continha. O que não quer dizer que se negue à empresa o direito de despedir
representantes por motivos legítimos. A indenização corresponde a uma despedida
injusta ou a uma rescisão arbitrária do contrato"19.

A edição da lei, portanto, veio suprir essa demanda de importante setor da economia brasileira. A insegurança jurídica, como sói acontecer, tende a gerar um ambiente hostil para os negócios.

Quando tudo parecia assentado, eis que o legislador pátrio decide criar um novo contrato, no Código Civil, o contrato de agência, muito semelhante ao contrato de representação comercial autônoma. A segurança jurídica, tão celebrada, acaba por se encontrar vulnerada quando o legislador não apresenta e justifica os motivos da edição desta nova figura contratual no Código Civil. A doutrina tenta identificar, mas as interpretações são diversas.

\section{Contrato de representação comercial e o contrato de agência: contratos idênticos ou distintos?}

Conforme vimos, o artigo $1^{\circ}$ da Lei 4.886/65 não definiu especificamente o contrato de representação comercial, mas sim o sujeito que exerce a atividade. Desse modo, dispôs que exerce a representação comercial autônoma a pessoa jurídica ou a pessoa física, sem relação de emprego, que desempenha, em caráter não eventual por conta de uma ou mais pessoas, a

19 Barbosa Lima Sobrinho. Emendas do Senado ao Projeto $n^{\circ}$ 2704-B, de 1961. Disponível em: http://www.camara.gov.br/proposicoesWeb/prop_mostrarintegra?codteor=1203088\&filename=Dossie+PL+2704/1961) 
mediação para a realização de negócios, agenciando propostas ou pedidos para transmiti-los aos representados, praticando ou não atos relacionados com a execução dos negócios.

Da leitura do texto legal é possível extrair as principais características do contrato de representação comercial, tais como a profissionalidade do representante, no sentido de que este deve ter como profissão o agenciamento de negócios, por meio de propostas ou pedidos encaminhados aos representados, sendo necessário, portanto, o registro no órgão de classe. A autonomia, ao prever a não subordinação hierárquica do representante ao representado. A habitualidade dos atos praticados pelos representantes, por não ser apenas a realização de um ato esporádico que caracteriza a representação. A delimitação geográfica das atividades dos representantes, significando que o representante deve ter uma zona geográfica específica de atuação. A exclusividade da representação diz respeito ao fato de não poder um representante representar duas ou mais sociedades empresárias para um mesmo gênero de negócios (o contrato, no entanto, pode prever de forma diversa). A remuneração é também característica deste contrato, pois se trata de um contrato oneroso. A remuneração do representante é devida até mesmo em atos em que o mesmo não interfira em zonas de sua exclusividade (art. 31, da Lei 4886/65).

Portanto, o contrato de representação comercial autônoma é um contrato bilateral (pois produz direitos e obrigações para ambas as partes), consensual, paritário, não solene (embora seja recomendável o contrato escrito, especialmente para fins probatórios numa eventual reclamação trabalhista), oneroso, de execução sucessiva e comutativo (pela equivalência das prestações).

Quanto ao contrato de agência, o Código Civil Interpretado, dos professores da UERJ Gustavo Tepedino, Heloísa Helena Barbosa e Maria Celina Bodin de Moraes, afirma os seus elementos essenciais. Vejamos:

\footnotetext{
"Para que se configure o contrato de agência, mostra-se indispensável: i) que uma parte tenha se obrigado a promover certos negócios à conta da outra. $\mathrm{O}$ agente, desse modo, apenas promove as atividades do agenciado, sem necessariamente representálo; ii) que a obrigação assumida seja desempenhada de forma habitual (caráter não eventual); iii) que os serviços a serem prestados estejam circunscritos à zona geograficamente determinada, independentemente de sua efetiva extensão, desde que seja certa; iv) que pelos serviços prestados decorra o direito a uma remuneração, por se o contrato de agência um contrato oneroso; v) que não haja qualquer vínculo de dependência (relação de emprego, prestador de serviços, subordinação hierárquica ou dependência econômica) entre as partes”(TEPEDINO; BARBOSA; MORAES, 2006, p.489).
} 
Assim, a primeira característica do contrato de agência é a habitualidade, como se vê do caput do artigo 710, do Código Civil de 2002, quando fala em não eventualidade. Logo em seguida, o artigo se refere à ausência de dependência do agente, o que indica a sua autonomia, pois não há vínculo de emprego. No parágrafo único do artigo 710 do Código Civil temos mais uma característica do contrato de agência: o agente pode ser nomeado mandatário do proponente e, com isso, ele próprio firmar o contrato final, em nome do proponente.

O objeto do contrato de agência é a realização de negócios pelo agente, que pode ser uma pessoa física ou jurídica, em zona determinada, mediante remuneração, chamada também de comissão, na qual o agente atua à conta do seu contratante, chamado de proponente, e recebe dele instruções para consecução do negócio. O Código Civil Comentado organizado pelo exMinistro do Supremo Tribunal Federal, Cezar Peluzo, classifica o contrato de agência da seguinte forma:

\footnotetext{
"Trata-se de contrato consensual, porque aperfeiçoado sem a exigência de forma especial; bilateral, porque, uma vez firmado induz direitos e deveres a ambas as partes, oneroso, devido à remuneração ao agente (art. 714) e intuiu personne, porquanto baseado na confiança que o preponente deposita no agente, daí dizer-se personalíssimo e intransferível. Seu objeto é o desempenho, pelo agente, de atividade voltada à obtenção ou à promoção de negócios e favor do agenciado, do preponente" (PELUZO, 2013, p.710).
}

Da análise das características dos contratos de representação comercial autônoma e de agência, verifica-se que ambos têm por objetivo a mediação entre as partes para a realização de negócios. Os pontos de aproximação entre o contrato de representação comercial e o de agência são muitos, tais como a habitualidade, a autonomia, consubstanciada na ausência de vínculo empregatício, a necessidade de estar condicionado às instruções do contratante, etc.

A grande questão que se coloca então é que desde 1965 já existe uma lei que regulamenta uma profissão e o contrato celebrado pelo exercente daquela profissão, que é o representante comercial (Lei 4.886/65). Diante disso, qual seria a razão de o Código Civil de $2002^{20}$ apresentar um conceito de agente que se amolda perfeitamente ao conceito de representante, ou seja, a habitualidade, sem relação de emprego, podendo ou não praticar atos de execução? O Codex define o agente nos moldes do representante comercial. No entanto, no momento de orientar o contrato, o Código Civil regulou de forma diversa, o que gera um imenso problema, apto a gerar diversas interpretações.

${ }^{20}$ O Código Civil de 1916 não tratou do contrato de agência. 
A doutrina tenta enfrentar as seguintes indagações: Qual teria sido o objetivo do Código Civil ao regular o contrato de agência? Seria revogar o contrato de representação comercial e ter apenas o contrato de agência? Mas como ficaria a parte referente ao exercício da profissão? Teria havido derrogação? Como ficariam então os dispositivos de representação que não são regulados no Código Civil? Porque a disciplina do contrato de representação é muito mais casuística do que o contrato de agência, que tem apenas 11 artigos. Se o Código Civil não revogou, qual seria o motivo desta regulação própria, se já existe uma legislação especial muito mais casuística? Ou seja, por que o contrato de agência foi regulado no Código Civil se já se tinha a mesma atividade regulada em lei especial de modo muito mais completo? São vários questionamentos, com diversas interpretações, a criar uma verdadeira celeuma doutrinária quanto à definição da regulação dos contratos de agência e representação comercial autônoma.

A exposição de motivos do Código Civil Brasileiro não ajuda a esclarecer os questionamentos. Lá se diz simplesmente que:

“A reformulação do contrato de agência e distribuição para atender à lei especial que disciplina a matéria sob o título impróprio de "representação comercial”. As ponderações feitas pelos interessados foram levadas na devida conta, o que vem, mais uma vez, confirmar a diretriz seguida no sentido de se procurar sempre a solução normativa mais adequada aos distintos campos de atividade, conciliando-se os interesses das categorias profissionais com as exigências da coletividade” (BRASIL, 2005, p.44).

Assim, o legislador não deixou claro qual foi o objetivo ao tratar do contrato de agência no Código Civil. Os professores Alexandre Assumpção e Pedro Teixeira explicam:

"Procedendo a análise do referido trecho destacado da Exposição de Motivos do
Código Civil de 2002, conclui-se que, se o objetivo era reformular o contrato de
agência para atender à regulamentação especial, a primeira impressão seria de
revogação da Lei n. 4.886/65. Porém, a parte final do trecho destacado da Exposição
de Motivos corrobora o entendimento de que os contratos de representação comercial
e agência são diferentes, ao destacar que o objetivo da reformulação proposta seria
encontrar uma solução adequada para os distintos campos de atividade, conciliando -
e não adequando - os interesses dessas diferentes categorias profissionais -
representante comercial e agente” (ALVES; TEIXEIRA, 2015, p.247).

Com o advento do Código Civil de 2002, a maior parte da doutrina considera os institutos jurídicos idênticos. Por todos, vale a pena citar, ainda que longa, a posição de Orlando Gomes, que sintetiza boa parte da posição dos que defendem serem os contratos idênticos ${ }^{21}$ :

"Em primeiro lugar, da análise comparativa dos dois textos legais parece não haver dúvida de que se trata do mesmo tipo contratual. Com efeito, a função econômicosocial do contrato descrito no art. 710 do Código Civil é idêntica à do contrato regulado pela Lei 4.886/65, a saber, a realização de determinada atividade (promoção

\footnotetext{
${ }^{21}$ Para uma análise detalhada e com posicionamento doutrinário de diversos juristas sobre a questão de se os contratos de agência e representação comercial são distintos ou idênticos, recomendamos a leitura do artigo dos professores Alexandre Assumpção e Pedro Teixeira já referenciado.
} 
de negócios em certa área, à conta e, eventualmente, também em nome de outrem) contra uma retribuição.

A distinção entre eles cinge-se apenas ao fato de que o art. $1^{\circ}$ da Lei $n^{\circ} 4.886 / 65$ limita a atividade do agente à promoção de "negócios mercantis", ao passo que o art. 710 do Código Civil de 2002 refere-se, de modo mais amplo, à promoção de "certos negócios”. A mudança deve-se à unificação do direito das obrigações operada pelo no Código.

Desse modo, atualmente o contrato de agência encontra-se regulado precipuamente pelas normas gerais contidas no Código Civil de 2002, mas também pelas normas da Lei 4.886/65. O que justifica a manutenção dois corpos normativos a regular o mesmo tipo contratual é a peculiaridade da agência regulada na Lei $n^{\circ} 4.886 / 65$. Esta, ao contrário do tipo previsto no Código Civil, tem por objeto a promoção de negócios mercantis, de modo a constituir um subtipo do contrato de agência. (...)

Dito isto, deve-se analisar a recíproca influência existente entre o Código Civil e a lei do representante comercial. Tendo em vista que as regras gerais do primeiro fixam a disciplina básica do tipo contratual, devem ser consideradas revogadas as normas da Lei n 4.886/65 incompatíveis com as do Código Civil. É o caso, v.g., do art. 31, parágrafo único, segundo o qual a exclusividade da prestação, em favor do agente, não se presumia caso não houvesse ajuste expresso, norma contrária à primeira parte do art. 711 do Código Civil; e também do art. 34, que condicionava a resilição unilateral do contrato, quando celebrado por tempo indeterminado, a aviso prévio de 30 (trinta) dias, incompatível com o art. 720 do Código Civil), que exige aviso prévio de, no mínimo, 90 (noventa) dias, podendo ser superior quando necessário em virtude dos investimentos realizados pelo agente.

Por outro lado, dada a peculiaridade do subtipo de agência regulado na Lei ${ }^{\circ}$ 4.886/65, somente a ele se aplicarão as normas específicas nela contidas, notadamente aquelas relativas à obrigatoriedade de inscrição do agente no respectivo Conselho Regional de Representantes Comerciais. Entretanto, as normas de índole geral constantes da lei do representante mercantil poderão ser aplicadas ao contrato de agência cujo objeto for a promoção de negócios não-mercantis.. É o caso, v.g, da regra que enumera as causas justificativas da resilição unilateral do contrato, contida nos arts. 35 e 36 do diploma legal” (grifos nossos) (GOMES, 2009, p.450).

Portanto, para Orlando Gomes, trata-se de um mesmo contrato no qual incidem dois corpos normativos, sendo o contrato de representação um subtipo do contrato de agência. A Lei 4.886/65 teria um âmbito de atuação mais especifico, pois, segundo o doutrinador, a incidência desta lei seria apenas aos contratos empresariais.

Os professores Gustavo Tepedino, Heloisa Helena Barbosa e Maria Celina Bodin de Moraes parecem compartilhar do mesmo entendimento. Eles afirmam que:

“As regras da L. 4.886/1965, por regularem a representação comercial, continuam vigentes no espectro de sua incidência, cingindo-se aos contratos de agência que tenham por objeto a promoção de negócios de natureza empresarial. Se o negócio a ser promovido tiver outra natureza, tais regras não se aplicarão a este específico contrato de agência, prevalecendo a disciplina codificada" (TEPEDINO; BARBOSA; MORAES, 2006, p.491).

Paulo de Araújo, no mesmo sentido, afirma que “o agente pode promover negócios de qualquer pessoa, seja ela empresária ou não. O representante comercial está restrito, seus representados serão sempre empresários” (ARAÚJO, 2011, p. 47). 
O processualista Humberto Teodoro Júnior amplia ainda mais o âmbito de atuação do representante comercial, identificando-o como sinônimo de agente, ao afirmar que "o novo Código Civil, a exemplo do direito europeu, abandonou o nomem iuiris de 'representante comercial', substituindo-o por 'agente'. Sua função, porém, continua sendo exatamente a mesma do representante comercial autônomo” (THEODORO JÚNIOR, 2002, p. 130). Ele soluciona o conflito de leis sob o critério temporal. Lei posterior revoga lei anterior com ela incompatível. Assim, o Código Civil teria revogado a lei de representação comercial no que com ele for incompatível.

Fran Martins afirma textualmente que “o contrato de representação comercial é também chamado de contrato de agência, donde representante e agente comercial terem o mesmo significado” (grifos no original) (MARTINS, 2017, p.128). Paula Forgioni, na mesma direção, acentua: "Não se deve considerar a introdução do contrato de agência como uma novidade em nosso ordenamento, porque a diferença entre agência e representação comercial é meramente terminológica e não substancial” (FORGIONI, 2005, p.112).

É sempre pertinente trazer à baila o posicionamento de Rubens Requião, que acredita que os contratos são distintos:

Melhor teria sido se a lei houvesse adotado distinção entre as duas figuras, de modo
que, na prática cotidiana do comércio, pudesse perceber-se logo à primeira vista, pelo
simples enunciado da denominação, se estaria ou não o sujeito investido de poderes
para concluir negócios. O agente comercial seria, dessa forma, o simples agenciador
de propostas ou pedidos para transmiti-los ao representado, ao passo que o
representante comercial seria quem praticasse atos relacionados com a execução dos
negócios, para usar-se da mesma terminologia do art. $1^{\circ}$ da Lei 4.886/65 (REQUIÃO,
2005, pp 48-49).

Assim, o famoso comercialista considera, na mesma linha de pensamento apresentada por Francisco Cavalvanti Pontes de Miranda, que “a diferença fundamental existente entre os contratos reside na outorga ou não de poderes ao representante para conclusão dos negócios mediados em favor do representado” (MIRANDA, 2012. Apud: ALVES; TEIXEIRA, 2015, p.245) $)^{22}$.

${ }^{22}$ Pontes de Miranda também reconhece a distinção entre o contrato de agência e representação comercial
autônoma: "O agente não se há de confundir com o representante, nem com a agência de empresa. A própria
referência, no mesmo texto, ao representante e ao agente é de repelir-se. A isso não se forrou o direito alemão. O
agente que conclui não é simples agente: há o plus da representação, ou da comissão. O agente em senso próprio,
intermedeia, sem se encarregar de conclusões de negócios jurídicos. Ou se ocupa de vendas, ou de compra, ou de
transporte, ou de seguros; não vende, não compra, não transporta, não segura. Se o auxiliar conclui, ou é
mandatário, ou procurador, ou comissionário. O contrato de representação não se pode confundir com o contrato
de agência: agenciar não é fazer o negócio, não é concluir contratos ou outros negócios jurídicos" (MIRANDA,
Francisco Cavalcanti Pontes de. Tratado de Direito Privado. Atualizado por MARQUES, Claudia Lima;
MIRAGEM, Bruno. t. XLIV - São Paulo: Revista dos Tribunais, 2012. Apud: ALVES; TEIXEIRA, 2015, p.245. 
Da análise dos textos normativos, em exercício hermenêutico à luz da coerência e razoabilidade que devem conduzir o intérprete na análise do ordenamento jurídico, é preciso identificar algumas premissas e rechaçar outras, de modo a prover uma leitura que dê maior adequação e racionalidade ao sistema jurídico.

Assim, parece-nos inconteste de dúvidas de que o contrato de representação comercial autônoma, regulado pela Lei 4.886/65, e o contrato de agência, regulado pelo Código Civil, são contratos distintos, apesar de tratarem da mesma atividade, a mediação para negócios.

Parece-nos equivocado o posicionamento doutrinário que afirma que os contratos em questão são, na verdade, o mesmo contrato. Isso porque, a nosso ver, não faria sentido existirem duas leis regulando exatamente o mesmo contrato. Se assim fosse, a hipótese seria de sucessão da lei no tempo. Nesta perspectiva, o Código Civil teria revogado a lei de representação comercial. Não nos parece ser esta a leitura correta, pois a própria Exposição de Motivos do Código Civil demonstra a coexistência de ambos os contratos. Os defensores de que os contratos são idênticos frequentemente não abordam a problemática de haver duas normas distintas tratando do mesmo contrato.

A leitura que apresenta a atividade do representante comercial como afeta apenas às atividades empresariais, tendo em vista a expressão “negócios mercantis” empregada pela Lei 4.886/65, ao passo que o contrato de agência teria âmbito de atuação mais amplo, por abrigar “negócios civis”, também não parece adequada. Isso porque o Código Civil de 2002 aboliu a distinção entre atividades mercantis e atividades civis. Neste diapasão, “não haveria porque reservar ao representante comercial apenas a mediação de negócios mercantis e ao agente de negócios civis, privativamente” (ALVES; TEIXEIRA, 2015, p.237). O Código Comercial fazia distinção entre obrigações mercantis de obrigações civis. No entanto, esta diferença não mais subsiste no ordenamento jurídico brasileiro. Assim, utilizar este critério para distinguir os contratos não nos parece adequado.

A nosso sentir, a leitura mais consentânea com o ordenamento jurídico é aquela que apresenta os contratos como sendo contratos distintos, de modo a evitar certa "promiscuidade" quando na aplicação das leis. Com a precisão de costume, Alexandre Ferreira Assumpção Alves e Pedro Freitas Teixeira explicam:

"O fato de a atividade ser a mesma, haja vista não se identificar traços distintivos na Lei $n^{\circ} 4.886 / 65$ no cotejo com o Código Civil, não significa que a regulamentação e as consequentes proteções e garantias sejam idênticas; Prova desta afirmativa é a ausência da previsão de registro profissional para o agente no Código Civil. 
Tal interpretação poderia causar no processo hermenêutico uma busca apenas pelos bônus, em detrimento dos ônus e deveres que também fazem parte de qualquer profissão regulamentada. Em síntese: se o Código Civil não tratou da obrigatoriedade do registro profissional dos agentes e a Lei n. 4.886/65 o fez em seu art. $2^{\circ}$, a interpretação do art. 721 reconhecendo que a segunda é a "lei especial” e, como tal, deve complementar as disposições do primeiro, implicaria na imposição do registro tanto ao agente quanto ao representante comercial, afastando-se dos objetivos previstos na Exposição de Motivos quando tratar de conciliar os interesses profissionais das categorias com as exigências da coletividade” (ALVES; TEIXEIRA, 2015, p. 249).

De fato, a maior diferença entre a representação e a agência está na necessidade de registro por parte do representante, conforme determina o artigo $2^{\circ}$ da Lei 4.886/65:

“Art. $2^{\circ}$ - É obrigatório o registro dos que exerçam a representação comercial autônoma nos Conselhos Regionais criados pelo art. $6^{\circ}$ desta Lei.

Parágrafo único. As pessoas que, na data da publicação da presente Lei, estiverem no exercício da atividade, deverão registrar-se nos Conselhos Regionais, no prazo de 90 dias a contar da data em que êstes forem instalados.”

Desse modo, aqueles que querem exercer a profissão de representante comercial devem se registrar no órgão de classe, no CORE na zona em que atua, e no CONFERE, pois se trata de uma profissão regulamentada. O agente, por sua vez, não necessita do registro para atuar como agenciador de propostas, mas não pode, igualmente, valer-se dos benefícios do representante inscrito no órgão de classe. Imagine-se a inusitada situação jurídica. Se para atuar como representante não fosse obrigatório o registro no órgão de classe, a consequência imediata seria a não inscrição dos agentes nestes órgãos, pois voluntariamente poucos ou talvez ninguém estaria disposto a pagar a anuidade do Conselho Regional dos Representantes Comerciais se pudessem usufruir de todos os benefícios como não associados.

É de se afirmar que, se o agente não está obrigado a se registrar, como está o representante, visualiza-se situações jurídicas distintas. E assim devem ser tratadas. O sujeito pode escolher ser agente ou representante comercial autônomo e, assim, submeter-se ao regime jurídico respectivo ${ }^{23}$.

${ }^{23}$ Há diversas distinções entre os contratos, a principal delas consistente na necessidade do registro do representante comercial. A hipótese de resolução contratual também são distintas (o prazo no Código Civil para denunciar o contrato é de 90 dias. No Código Civil é de apenas 30 dias (arts. 34, da Lei 4.886/65 e art. 720, do CC/02); O representante tem direito a no mínimo 1/12 avos por rescisão imotivada do contrato (art. 27, "J" da lei). Na falência, o art. 44 da Lei especial, prevê a equiparação das comissões devidas ao representante aos créditos de natureza trabalhista. Os créditos na agência gozam de privilégio geral. Há distinção também quanto à exclusividade. No contrato de representação, a exclusividade para atuar como representante deverá estar expressa no contrato. O CC/02, de forma diferente, presumiu a exclusividade de atuação. A lei especial confere um tratamento privilegiado ao representante para julgamento das controvérsias , sendo competente a Justiça Comum e o foro do domicílio do representante, entre outras distinções (artigo 39, da Lei 4.886/65). 


\title{
A DISCIPLINA JURÍDICA DOS CONTRATOS DE REPRESENTAÇÃO COMERCIAL
} AUTÔNOMA E AGÊNCIA.

Neste ponto, novamente com os professores Alexandre Ferreira Assumpção Alves e

Pedro Freitas Teixeira, que defendem o mesmo posicionamento, concluem de forma categórica e, ao nosso sentir, com muita correção:

\begin{abstract}
“A atividade de mediação de negócios à conta de outrem em uma zona exclusiva e geograficamente delimitada, em troca de uma remuneração/comissão pré-fixada, pode ser realizada tanto pelo representante como pelo agente, porém para ser representante comercial, a pessoa natural ou jurídica terá que estar devidamente registrada no CORE da zona que atua e no CONFERE, o que lhe garantirá uma série de deveres e obrigações, conforme analisado ao longo desse trabalho, mas também prerrogativas e privilégios.

Caso contrário, se o mediador não apresentar o devido registro no órgão de classe, este será considerado agente, na forma dos arts. 710 a 721, do Código Civil de 2002. A própria Exposição de Motivos do Código Civil foi clara ao esclarecer que a disciplina do contrato de agência tinha por objetivo compatibilizar os interesses das categorias.

Com isto, os contratos devem ser identificados a partir do profissionalismo caracterizado pelo registro profissional, sem que a ausência deste impeça a atuação do agente, mesmo em caráter habitual. Sem embargo, não poderá o agente invocar os benefícios e prerrogativas previstos na Lei n. 4.886/65, para ampliar a regulamentação do Código Civil a seu favor.

Este entendimento, para além de permitir a proteção dos representantes comerciais, garantindo vigência às regras específicas, evita que haja um esvaziamento da profissão e o estímulo ao cancelamento do registro profissional, sob a alegação de que este passou a ser facultativo desde que o contrato celebrado seja de agência. Com isto o agente poderia invocar dispositivos protetivos da Lei n. 4.886/65 ao representante comercial, por força do art. 721 do Código Civil. Tal não pode prevalecer” (ALVES; TEIXEIRA, 2015, p. 252).
\end{abstract}

\section{Conclusão}

A conclusão de que os dois contratos, representação comercial autônoma e agência, convivem a partir da necessidade do registro nos parece bem fundamentada e adequada. Criase um critério objetivo e seguro para distinguir as duas figuras jurídicas, assim como delimita as hipóteses de incidência de um ou outro contrato. Em suma, o contrato de agência, celebrado pelo agente livre, segue as normas do Código Civil, enquanto o contrato celebrado pelo representante comercial registrado segue as regras da Lei 4.886/65. Quer-se dizer que, com registro, é representante comercial, sem registro, é agente.

Com efeito, se o Código Civil regulou de modo diferenciado, não pode ser para que se tenha o mesmo contrato. Também não é admissível que a intenção tenha sido revogar a lei específica e criar uma série de lacunas. Os dispositivos convivem no ordenamento jurídico. O que não pode ocorrer, de modo algum, é o intérprete selecionar a norma mais favorável de cada campo normativo e aplicá-la de acordo com sua conveniência. O requisito do profissionalismo é um elemento de distinção seguro entre os contratos de representação e agência. Mesmo porque, optar pelo registro traz consequências jurídicas distintas daquele que opta por não se 
registrar ${ }^{24}$. Assim, ou se aplica o contrato de representação como um todo (Lei 4.886/65) ou o contrato de agência como um todo (artigos 710 a 721 do Código civil).

Destarte, não se pode afirmar que os contratos de representação comercial autônoma e agência são idênticos. De fato, a atividade realizada tanto pelo representante comercial autônomo como pelo agente é de mediação de negócios à conta de outrem, em uma zona exclusiva e geograficamente delimitada, em troca de remuneração ou comissão. No entanto, cada contrato tem disciplina normativa própria e o corte para distinguir se o agente auxiliar do comércio é representante ou agente é verificar a inscrição no devido órgão de classe. Sendo positiva a resposta, tratar-se-á de representante comercial autônomo, com os deveres e obrigações pertinentes. Caso o agente escolha não fazer o registro, não lhe será vedado exercer tal atividade, homenageando-se o princípio da livre iniciativa, mas não terá, contudo, os benefícios do representante profissional registrado.

\section{REFERÊNCIAS BILIOGRAFICAS}

ALVES, Alexandre Ferreira de Assumpção; TEIXEIRA, Pedro Freitas. “A [des] identidade do contrato de representação comercial diante do contrato de agência”. In: REZENDE, Elcio Nacur; RODRIGUES JÚNIOR, Otávio Luiz; OLIVEIRA, José Sebastião (org.). Direito civil contemporâneo [recurso eletrônico online]. Florianópolis: CONPEDI, 2015, p. 230. Disponível em: https://www.conpedi.org.br/publicacoes/c178h0tg/aynm5hh3/9z7SsTJX00TNbkj4.pdf. Acessado em: 27/02/2018, às 18:46.

ANTONETTI, Guy. A economia medieval. São Paulo: Atlas, 1977.

ARAUJO, Paulo Dorón Rehder de. “Contrato de representação comercial”. In: FERNANDES, Wanderley (org.), Contratos de organização da atividade econômica. São Paulo: Saraiva, 2011.

BRASIL. Câmara dos Deputados - Projeto de Lei n. 1.171, de 1949 - Protocolo n. 0242. Deputado Campos Vergal.

Exposição de motivos $\boldsymbol{n}^{\circ}$ 355, de 1965, do Ministro da Indústria e Comércio, p. 6.

Disponível

em: http://www.camara.gov.br/proposicoesWeb/prop_mostrarintegra?codteor=1194993\&filename =Dossie+-PL+3350/1965. Acessado em: 08 de março de 2018.

\footnotetext{
${ }^{24}$ Conforme explicitado na nota de rodapé anterior.
} 
. Novo Código Civil: exposição de motivos e texto sancionado. 2.ed. Brasília: Senado

Federal, Subsecretaria de Edições Técnicas, 2005.

COMPARATO, Fábio Konder. A Civilização capitalista: para compreender o mundo em que vivemos. São Paulo: Saraiva, 2013.

DELGADO, Maurício Godinho. Trabalho autônomo. In.:Curso de Direito do Trabalho, 6. ${ }^{a}$ edição. São Paulo: Ed. Ltr, 2007.

FORGIONI, Paula. Contrato de Distribuição. São Paulo: Revista dos Tribunais, 2005.

GOMES, Orlando. Contratos. 26 a ed. Rio de Janeiro: Forense, 2009.

KEHOE, Dennis P. \& MCGINN, Thomas A. J. (eds.). Ancient law, ancient society. Ann Arbor: University of Michigan Press, 2017.

LE GOFF, Jacques. Mercadores e banqueiros da Idade Média. São Paulo: Martins Fontes, 1991.

LEITE, Carlos Henrique Bezerra. Curso de Direito do Trabalho. $8^{\text {a }}$ ed. São Paulo: Saraiva, 2017.

MARTINS, Fran. Contratos e obrigações comerciais. 17 ${ }^{\text {a }}$ ed. Rio de Janeiro: Forense, 2017.

MCGAW, M.C. A history of the common law of agency with particular reference to the concept of irrevocable authority coupled with an interest. Tese de doutorado. University of Oxford: (United Kingdom), Ann Arbor, 2005.

MOQUIN, Arnaud. Commercial agent Contract: France. Disponível em: http://www.eiure.com/pdf/agency/2007/france.pdf. Acessado em 07/03/2018.

PELUZO. Cezar (coord.). Código Civil comentado: doutrina e jurisprudência: Lei n. 10.406, de 10.01.2002: contém o Código Civil de 1916. $7^{\mathrm{a}}$ ed. Barueri/SP: Manole, 2013.

REQUIÃO, Rubens. Aspectos jurídicos da representação comercial. Dissertação de livredocência apresentada à Faculdade de Direito do Paraná. Curitiba: Universidade do Paraná, 1950.

Curso de direito comercial. 23a ed. São Paulo: Saraiva, 1998.

Do Representante Comercial. Rio de Janeiro: Forense, 1977.

Do representante comercial: comentários à Lei $n^{\circ} 4.886$, de 9 de dezembro de 1965,

à Lei 8,420, de 8 de maio de 1992, e ao Código Civil de 2002. Rio de Janeiro: Forense, 2005. SAAD, Ricardo Nalim. Representação comercial. 4a ed., São Paulo: Saraiva, 2008.

SOBRINHO, Barbosa Lima. Emendas do Senado ao Projeto ${ }^{\circ}$ 2704-B, de 1961.Disponível em: 
http://www.camara.gov.br/proposicoesWeb/prop_mostrarintegra?codteor=1203088\&filename =Dossie+-PL+2704/1961). Acessado em 21/03/2018.

STORY, Joseph. Commentaries of the Law of Agency as a Branch of Commercial and Maritime Jurisprudence, With Occasional Illustrations From the Civil and Foreign Law. Boston: Little Brown, and Company, 1869.

TEPEDINO, Gustavo; BARBOZA, Heloisa Helena; MORAES, Maria Celina Bodin. Código Civil interpretado conforme a Constituição da República. Vol. II. Rio de Janeiro: Renovar, 2006.

THEDORO JÚNIOR, Humberto. “Do Contrato de agência e distribuição no novo código civil”. Revista da Faculdade de Direito de Minas Gerais, n 42, p. 129-163, 2002. 